\title{
Examining Co-activation Through Cross-Linguistic Influence among Bilinguals in Spoken Language Processing: Evidence from Eye Movements
}

\author{
OR-KAN, SOH \\ School of Language Studies \& Linguistics \\ Faculty of Social Sciences \& Humanities \\ Universiti Kebangsaan Malaysia, Malaysia \\ HAZITA AZMAN \\ School of Language Studies \& Linguistics \\ Faculty of Social Sciences \& Humanities \\ Universiti Kebangsaan Malaysia, Malaysia \\ hazita@ukm.edu.my \\ HO SU MEI \\ School of Language Studies \& Linguistics \\ Faculty of Social Sciences \& Humanities \\ Universiti Kebangsaan Malaysia, Malaysia
}

\begin{abstract}
The aim of this paper is to examine the cross-linguistic influences of both early and late bilinguals in spoken language processing and the differences between them. There were four undergraduates, comprising of two early and two late bilinguals, participated voluntarily in this research. The Tobii X 300 was used as the equipment to be applied when measuring and recording the eye-movements of students. Four conditions, namely between competition, within competition, simultaneous competition, and no competition, were designed as the stimuli. Findings were coded as containing zero or greater-than-zero fixations of each condition (if it was present) along with their respective filler (control). The presence of competition can be measured by employing time course sensitive response measures which is the time to first fixation. The results of this study have illustrated through the presence of cross-linguistic influence in bilinguals that the two languages in the bilinguals mind exist in a state of co-activation regardless of their age of acquisition, consistent with previous studies conducted. However, the age of acquisition of a bilingual's second language differentiates the type of cross-linguistic influence that a bilingual is likely to face when processing their second language.
\end{abstract}

Keywords: Co-activation; cross-linguistic; early and late bilinguals; spoken language processing; eye tracking

\section{INTRODUCTION}

Much of the current understanding and research conducted on bilingualism is founded upon the Inhibitory Control Model (ICM) which was first proposed by Green (1998) in an attempt to understand bilingualism. According to Green, the two languages in the bilingual's brain face competition during language processing and would therefore need to be inhibited for coherent language production. Modern research studies have identified the two languages in the bilingual mind as being in the state of co-activation, which is the state of having both languages always active to some extent thus creating unceasing competition for selection which therefore requires bilinguals to process language differently from monolinguals by exerting control in language processing (Bialystok, 2017). Consequently, such competition produces "interaction between two grammatical systems" known as cross-linguistic influences or interferences (Mishina-Mori, 2019; Zirnstein, Hell \& Kroll, 2019).

Additionally, the current state of the bilingualism literature has been surrounded with controversy due to mixed results that bilingualism has on cognition including language processing which has been attributed to the many individual differences (Supakorn, 2020; Valian, 2015; Fricke, Zirnstein, Navarro-Torress, \& Kroll, 2018). One such individual 
difference that requires attention is the Age of Acquisition (AoA). This is because the AoA is also often associated with language proficiency as the critical period for language development determines the level of possible proficiency especially in second language acquisition, which in turns affects the level of language activation in bilinguals as proposed by Grosjean (2001). However, there is a paucity of studies conducted on how AoA affects the bilingual experience specifically in the language processing context (Soh, Hazita \& Ho, 2020). Hence, this study aims to examine how individual difference in the AoA, which classifies bilinguals into early and late bilinguals, influences language processing. While early bilinguals are considered to have achieved native-like linguistic competence in two languages, late bilinguals acquire their second language only after acquiring their first language and are not able to achieve complete competence of their second language (Beardsmore, 1986; Moradi, 2014).

Furthermore, one of the predominant challenges widely known in the bilingualism literature is the lack of control in the nature of the tasks employed. Marian and Spivey (2003), as well as Valian (2015) have explained that the tasks employed such the well-known Stroop task, can be argued to have evoked both languages as the task required both languages to be active and thus resulted in cross-language influences. Hence, it does not conclusively provide evidence of the co-activation state in bilinguals since both languages were forced to be activated. Marian and Spivey (2003) have further suggested that co-activation should be examined in a condition without any explicit input or output of one of the two languages. Therefore, one of the ways in examining the presence of the co-active languages in bilinguals which fulfils such criteria is through spoken language comprehension coupled with eye tracking technology. This is because in spoken language comprehension, only one language input and output is required. In addition, eye tracking technology is employed as not only does it reveal language activation (Hajar Abdul Halim, 2020; Tanenhaus, Magnuson, Dahan \& Chambers, 2000; Conklin \& Pellicer-Sánchez, 2016; Aryadoust \& Ang, 2019) but also because eye moments allow for the recording of activation without stimulating the language in any way throughout the entire experiment.

The present study is guided by the following research questions:

- What are the cross-linguistic influences of both early and late bilinguals in spoken language processing?

- What are the differences between the cross-linguistic influence of early and late bilinguals in spoken language processing?

\section{LITERATURE REVIEW}

\section{CROSS-LINGUISTIC INFLUENCES IN BILINGUAL AND SPOKEN LANGUAGE PROCESSING}

It has been generally accepted that a bilingual is someone who has the ability to access or use more than one language (Hamers \& Blanc, 1983) and Chan and Abdullah (2015) have further reiterated bilingualism as the ability to grasp and flawlessly comprehend two languages. However, this ability to comprehend and use two languages produces competition in the bilingual's brain which gave rise to Green's (1998) Inhibitory Control Model (ICM) proposing the need for inhibition in order for coherent language production. Many researchers have since studied the results of such competition concluding that this competition enhances the executive function of the brain thus producing what is known as a bilingual advantage in terms of mental flexibility, problem solving skills and even the delay of Alzheimer's disease (Bialystok \& Martin, 2004; Leikin, 2012; Antoniou, 2019; Bialystok, Craik, \& Freedman, 2007). However, researchers have also discovered evidence of "interaction between two grammatical systems" 
which is known as cross-linguistic influence produced when bilinguals process language (Mishina-Mori, 2019). Such influences are typically further categorized and analysed as between-language (competition from first language into second language), within-language (competition occurring in either the first or second language) and simultaneous (competition from both between and within languages) (Marian \& Spivey, 2003; Blumenfeld \& Marian, 2005; Blumenfeld \& Marian, 2007; Blumenfeld \& Marian, 2013). These competitions are considered a processing cost as well as a by-product of co-activation for bilinguals when processing a language whether in reading, speaking or listening. In the study done by Marian and Spivey (2003), bilinguals face competition more heavily from within a language while competition from between languages still occurs. According to Bialystok (2017), the studies of cross-linguistic influences have proven that in the bilingual's mind, the two languages are always active to some extent and would compete for selection. The research carried out by Macizo (2016) has illustrated this by concluding that bilinguals co-activate the phonology in both languages in which L1 influences L2. Such findings have contrasted early research studies revealing the selective or independent nature of activation (Watkins \& Peynirioglu, 1983; Gerard \& Scarborough, 1989; Ransdell \& Fischler, 1987).

Much research has since been conducted examining cross-linguistic influences establishing the active state of both languages in both visual and auditory domains. However, a huge body of initial research focuses on the visual domain by employing comprehension of written materials such as the Stroop task, priming task and comprehension tests (Kidd, Chan, \& Chiu, 2015; Rossi et. al, 2017; Rabia, 2019). Subsequently, cross-linguistic influences in language processing were examined based on language production rather than language comprehension (Salleh et al., 2016; Strik, 2016). Evidence for cross-linguistic influences in spoken language processing particularly in comprehension itself has been scarce. Therefore, this current study aims to fill in a gap and to contribute to the literature in bilingual spoken language processing.

\section{EARLY AND LATE BILINGUALISM IN LANGUAGE PROCESSING}

There are many types of bilinguals. One type of the classification of bilinguals is based on the Age of Acquisition (AoA) of a bilingual's second language, classifying them into either early or late bilinguals. Beardsmore (1986) and Moradi (2014) have defined early bilinguals as achieving native-like linguistic competence in two languages while late bilinguals are those who acquire their second language only after acquiring their first language and are not able to achieve complete competence of their second language. According to Kovelman, Baker and Petitto (2008), the AoA is considered an influential factor in the study of bilingualism and language processing. This is because the AoA experience not only proves to be long-lasting and widespread, but that there are both conclusive and physical evidences such as fMRI scans of the effects of early and late bilinguals in language learning, processing and controlling mechanisms (Berken, Chai, Chen, Gracco \& Klein, 2016; Abutalebi, 2008; Rossi, Diaz, Kroll $\&$ Dussaias, 2017). To illustrate this, the study conducted by Archila-Suerte, Zevin, Bunta and Hernandez (2012) has demonstrated that bilinguals employed different ways in classifying non-native sounds depending on the cognitive processes available at the AoA.

Additionally, the AoA is also closely related with proficiency. Fromkin, Rodman and Hymans (2007) have explained that the language window of opportunity known as the critical period for language development, determines the level of possible proficiency especially in the second language. Based on the language mode hypothesis, the level of language activation is influenced by proficiency as proposed by Grosjean (2001). However in cross-linguistic influences, Kroll, Dussias, Bice and Perrotti (2015) have suggested that both languages L1 and L2 affect each other especially when a bilingual is proficient in the L2 as both L1 and L2 are 
interconnected. The study conducted by Kroll, Dussias, Bice and Perrotti (2015) has revealed evidence that contrasts initial findings claiming that late bilinguals reveal fewer cross-linguistic influences from L2 to L1. On the other hand, results have suggested that cross-language influences are bidirectional thus making both early and late bilinguals similar.

\section{EYE TRACKING IN BILINGUALISM AND LANGUAGE PROCESSING}

The use of eye tracking is on the rise especially in field of bilingualism and language processing. This is because the research on bilingualism is beset with controversial inconsistent results which according to Valian (2015) needs to be resolved on a large scale. According to Valian (2015), the different variations and types of tasks employed in the research of bilingualism contribute to the inconsistent results. Furthermore, Marian and Spivey (2003) have suggested the need for eye tracking as eye tracking allows for the detection of language activation without causing any overstimulation. The study done by Marian and Spivey (2003), has shown that frequent eye movement was made towards objects which names were phonologically similar in another language thus proving automatic parallel activation of mental lexicons during spoken language processing. Ratiu, Hout, Walenchok, Azuma and Goldinger (2017) have also proposed the use of eyetracking in studying possibly subtle differences as it allows for accuracy in measuring reaction time. Grosjean (2018) has further explained that this is because during spoken word processing, only a few milliseconds is needed to activate the internal lexicon of words that partially match the speech sound when triggered by the first sounds of speech. Additionally, Tanenhaus, Magnuson, Dahan and Chambers (2000) have pointed out that eyetracking allows researchers to study real-time language comprehension by examining the linking hypothesis in spoken language comprehension. Tanenhaus, Magnuson, Dahan and Chambers (2000) have asserted the use of time course sensitive response measures such as time to first fixation in order to examine competition for recognition as competition is activated when spoken word sound patterns are revealed over time.

\section{RESEARCH METHODOLOGY}

\section{PARTICIPANTS}

Four second year undergraduate students from the National University of Malaysia participated in this study. The participants were Malay-English bilinguals that took part in this research voluntarily. Two of the participants (P3 \& P4) were early bilinguals while the other two (P1 \& P2) were late bilinguals. After the experiment, 3 participants indicated that English was their preferred language while 1 participant indicated that both English and Malay was their preferred language. Participants estimated their use of English was limited to an average of about 7 hours a day (primarily in classes) and Malay was used the rest of the time. Table 1 shows the participants information based on their language history. The mean age of all the participants at the time of the experiment was 21 years.

TABLE 1. Demographic of participants

\begin{tabular}{|c|c|c|c|c|c|}
\hline $\begin{array}{l}\text { Participant } \\
\text { Number }\end{array}$ & Gender & $\begin{array}{c}\text { Current Age } \\
\text { (years; months) }\end{array}$ & $\begin{array}{l}\text { Acquired L2 Age } \\
\text { (years; months) }\end{array}$ & $\begin{array}{l}\text { Frequency of L1 } \\
\text { used (hrs per } \\
\text { week) }\end{array}$ & $\begin{array}{l}\text { Preferred } \\
\text { language }\end{array}$ \\
\hline 1 & $M$ & $22 ; 2$ & $7 ; 3$ & 77 & L2 \\
\hline 2 & M & $21 ; 5$ & $7 ; 7$ & 119 & L1 \& L2 \\
\hline 3 & $\mathrm{~F}$ & $23 ; 10$ & $3 ; 5$ & 66 & L2 \\
\hline 4 & $\mathrm{~F}$ & $23 ; 7$ & $3 ; 3$ & 70 & $\mathrm{~L} 2$ \\
\hline Mean & & $22 ; 12$ & $5 ; 5$ & 83 & \\
\hline SD & & $1 ; 3$ & $2 ; 2$ & 24 & \\
\hline
\end{tabular}


The Tobii X300 with $300 \mathrm{~Hz}$ sample rate was employed in order to examine and record the eye movements of the participants during the experiment. The Tobii X300 was selected as not only is it non-intrusive, but is able to capture the eye movements of the participants for extended periods of time without causing the participants to feel fatigued as slight natural head movements are allowed. A 40-60cm distance between a 19" LED screen and the participants was required, resulting in a $24 \times 18$ degree of the visual angle. As all the images were presented on the screen, the participants did not have to employ a mouse for scrolling but only show interaction with the stimulus through clicking.

\section{DESIGN OF STIMULUS}

The current study comprised of four conditions as modelled after Marian and Spivey (2003) which are the no-competition control condition, a between-language competition condition, a within-language competition condition as well as a simultaneous competition condition (see Figure 1). For each condition, 10 sets of four images were presented on the display - the target object, the conditioned competitor object, and the filler object. Objects chosen must be a noun, a physical object rather than abstract and must be displayed in similar sizes.

In the no-competition control condition, one of the four images was the target object while the other three were filler objects. In the between-language competition condition, one of the four images was the target object; one was the between-language competition object whose name in Malay overlapped with the English name of the target object, while the other two were filler objects. Similarly in the within-language competition, one was the target object; one was the within-language competition object whose name in English overlapped with the English name of the target object while the other two were fillers. In the final condition which is the simultaneous competition condition which tested both the between-language and withinlanguage competition together, one was the target object; one was the between-language competition object, the within-language competition object and one filler object. Each stimuli was chosen carefully in order to ensure that the overlap between and within languages were equal.

The order of the stimulus were pseudo-randomly arranged in order to avoid any target objects from appearing twice repeatedly. Two sets of instructions were given - one at the start of the recording whiles the other during the recording. The first sets of instructions were: (1) Four items will be presented to you in each page, (2) An audio instruction will then be played automatically as you enter the slide (Eg: "Click on the water bottle."), (3) Follow the audio instruction and click on the item stated. The second sets of instructions which were played during the recording were: (1) Click on the target object, (2) click on the filler object, (3) click another filler object. Participants were asked to click on the same filler object for the during the simultaneous competition condition. 


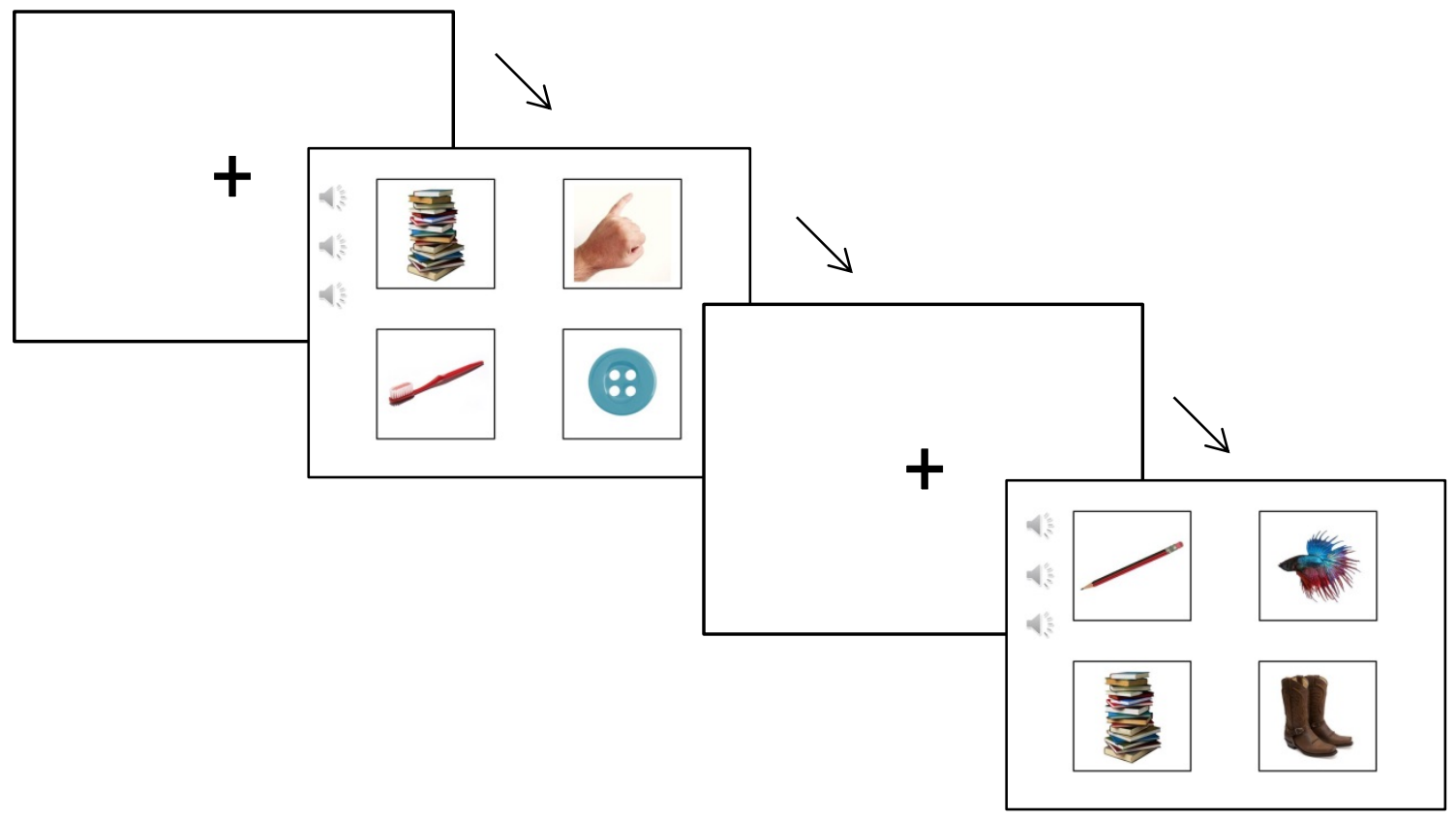

FIGURE 1. Examples of stimuli used during experimental trials

Figure 1 illustrates two examples of stimuli that is presented to the participants during experimental trials with the between language competition (second screen) and within language competition (fourth screen) conditions. In the between language competition condition, the target object (books) phonologically overlaps with the competitor object (button) in Malay which is 'butang'. In the within language competition condition the target object (books) and competitor object (boots) phonologically overlap in English.

\section{PROCEDURES}

Based on the language mode hypothesis by Grosjean (1998), it has been hypothesized that any awareness or detection of bilingualism in the experiment whether conscious or unconscious affects the results. Therefore, the voice of a monolingual English speaker was chosen from a free text to speech program to record the instructions. Additionally, no mention or use of the Malay language was present at any point before, during and after the experiment.

Participants were contacted by phone after they had been identified as fitting the criteria of being a Malay-English early bilingual (acquired English before age 6) or Malay-English late bilingual (acquired English after the age of 6) for this study, and participation was voluntary. Participants were informed that they were requested to be part of an experiment which examined their eye movements while following simple instructions. Participants were called to the experiment room individually and a short briefing of what the experiment would entail was conducted. Before the experiment, a standard 9-point calibration process was carried out. Each participant then went through the experiment of eye movement recordings of the 40 sets. After the completion of each session, participants were requested to fill out a language history questionnaire (see Appendix A).

\section{RESULTS}

Findings were coded as containing zero or greater-than-zero fixations of each condition (if it was present) along with their respective filler (control) (see Appendix B). As suggested by Tanenhaus, Magnuson, Dahan and Chambers (2000), presence of competition can be measured 
by employing time course sensitive response measures which is the time to first fixation. Participant's eye movements were coded as greater than ' 0 ' for fixations if participant's fixation duration of the region of interests remained for at least $33.3 \mathrm{~ms}$ after the time to first fixation. Analysis was carried out on each respective types of competition and results are reported in Table 2 and Table 3 as overall percentages.

RQ 1: What are the cross-linguistic influences of both early and late bilinguals in spoken language processing?

TABLE 2. Results for cross-linguistic influences of both early and late bilinguals

\begin{tabular}{lcc}
\hline Display & $\begin{array}{c}\text { Fixations of between-language } \\
\text { competitor }\end{array}$ & $\begin{array}{c}\text { Fixation of within language } \\
\text { competitor }\end{array}$ \\
\hline Between-language competitor present & $20 \%$ & $\mathrm{n} / \mathrm{a}$ \\
Within-language competitor present & $\mathrm{n} / \mathrm{a}$ & $25 \%$ \\
Both competitors present & $20 \%$ & $32.5 \%$ \\
$\begin{array}{l}\text { No competitor present } \\
\text { (control filler object) }\end{array}$ & $5 \%$ & \\
\hline
\end{tabular}

When between-language competition was present, participants would make eye movements towards the Malay competition 20\% out of the entire between-language competition stimulus presented and 5\% during the no competitor condition in which participants made eye movements towards the control filler in the same location. This indicates that during second language processing, bilinguals face competition from their first language.

In the within-language competition condition, participants made eye movements towards the within language competitor for a total of $25 \%$ and $5 \%$ at the non-overlapping control fillers during the no competition condition. The results suggest that bilinguals face within language competition in their second language processing.

During the simultaneous competition condition when both competitors are present, participants made eye movements towards the between language competitor $20 \%$ in total and eye movements towards the $32.5 \%$ out within language competition out of all the tests conducted. Respectively, results from both the between-language competition and within language competition condition as well as the simultaneous competition condition have indicated that bilinguals are more likely to face within language competition during spoken second language processing.

RQ 2: What are the differences between the cross-linguistic influence of early and late bilinguals in spoken language processing?

TABLE 3. Results for cross-linguistics influences of early and late

\begin{tabular}{|c|c|c|c|c|}
\hline \multirow[t]{2}{*}{ Display } & \multicolumn{2}{|c|}{$\begin{array}{c}\text { Fixations of between-language } \\
\text { competitor }\end{array}$} & \multicolumn{2}{|c|}{$\begin{array}{c}\text { Fixation of within language } \\
\text { competitor }\end{array}$} \\
\hline & Early & Late & Early & Late \\
\hline Between-language competitor present & $10 \%$ & $10 \%$ & $\mathrm{n} / \mathrm{a}$ & $\mathrm{n} / \mathrm{a}$ \\
\hline Within-language competitor present & $\mathrm{n} / \mathrm{a}$ & $\mathrm{n} / \mathrm{a}$ & $10 \%$ & $15 \%$ \\
\hline Both competitors present & $7.5 \%$ & $12.5 \%$ & $25 \%$ & $7.5 \%$ \\
\hline $\begin{array}{l}\text { No competitor present } \\
\text { (control filler object) }\end{array}$ & & & & \\
\hline
\end{tabular}

In the between-language competition condition, both early and late bilinguals made eye movements as much as $10 \%$ of the total conditioned stimulus toward the between language competitor and only 5\% during the no competitor condition in which participants made eye movements towards the control filler in the same location. This indicates that the amount of 
competition faced by both early and late bilinguals between languages during second language processing is equal.

During the within-language competition condition, early bilinguals face competition in only $10 \%$ of the conditions while late bilinguals face competition when a within-language competitor is present in $15 \%$ of the conditions. Results have shown that late bilinguals are more likely to face competition as much as $5 \%$ compared to early bilinguals in from within a language during second language processing.

When simultaneous competition is present, early bilinguals are more likely to make eye movements towards the within-language competitor (25\%) compared to the between-language competitor $(7.5 \%)$. On the other hand, late bilinguals would face competition from between languages more often $(12.5 \%)$ compared to within a language $(7.5 \%)$ when both competitors are present. These results have indicated that when simultaneous competition is present during second language processing, early bilinguals are more likely to face competition from within the language while late bilinguals face competition between languages.

\section{DISCUSSION}

RQ 1: What are the cross-linguistic influences of both early and late bilinguals in spoken language processing?

Results have indicated that not only does a bilingual face competition from within their second language, but also from their first language into their second. In situations which both competitors are simultaneously present, words that are phonologically overlapping from both within and between languages show competition for selection. Overall, bilinguals are more likely to face competition from within the language during second language processing. Such findings are in line with the pioneering study conducted by Marian and Spivey (2003) in which through vigorous controlled circumstances have shown that competition from within and between languages is present during second language processing and that the within language competition is found to be more likely even during second language processing.

Grosjean (2018) has asserted that during spoken word recognition, the first sounds of speech triggers lexical processing and that only a few milliseconds is required to activate the internal lexicon together with other words that partially match the speech signal. Grosjean (2018) further explained that as spoken words unfold, the possibilities compete and ultimately the target word is selected after the recognition system eliminates possibilities. In line with Green's (1998) ICM, such elimination occurs through inhibition of the various competitions. Results from this experiment concluding the presence of cross-linguistic influences from both between and within languages have revealed that bilinguals would need to employ inhibition when facing such competition in order to process second language and ultimately make the correct selection as theorized in Green's (1998) ICM. The need for inhibition would therefore suggest that the two languages in the bilingual's brain are always active to some extent even in situations that did not require the use or activation of one of the languages as in the current experiment. Findings are consistent with the explanation of Bialystok (2017) as well as Blumenfeld \& Marian (2013), along with past studies conducted by Marian and Spivey (2003) and Macizo (2016) establishing the co-activation state of the two languages in the bilinguals brain.

RQ 2: What are the differences between the cross-linguistic influence of early and late bilinguals in spoken language processing? 
Based on the results of the experiment, both early and late bilinguals face equal amount of competition from their first language into their second language when only a between language competitor is present during second language processing. These findings further substantiate the conclusion found in the study conducted by Kroll, Dussias, Bice and Perroti (2015) in which the researchers have explained that both early and late bilinguals are similar to some extent when it comes to cross-linguistic influences due to the bidirectional nature of the influences. Whereas in a situation where only within language competition is present during second language processing, it is more likely for late bilinguals to face competition from the within language competitor as compared to early bilinguals. Mavian and Spivey (2003) as well as Blumenfeld and Marian (2007) have hypothesized such results to be in relation with the fluency of languages in the late bilinguals but emphasizes that further research needs to be conducted in this aspect especially in second language processing.

However if both a within and between language competitor, it is more likely for late bilinguals to face competition from between languages while early bilinguals tend to face competition from within a language in second language processing. The evidence regarding late bilinguals in a simultaneous competition condition has proven to be in tandem with the research conducted by Kroll, Dussais, Bice and Perroti (2015) asserting that late bilinguals also face cross-linguistic influences from their first language into their second language when processing a second language. Findings replicate the results of the study conducted by Peristeri, Tsimpli, Sorace and Tsapkini (2018) in which late bilinguals face greater interference from their mother tongues compared to early bilinguals. Kroll, Dussais, Bice and Perroti (2015) have further explained that this is because of the interconnection shared by both the first and second language in which there exists a language storage that is shared to support both languages regardless of the type of language. On the other hand in the case of early bilinguals facing greater influences from within a language, Marian, Bartolotti, Rochanavibhata, Bradley and Hernandez (2017) and Or-Kan $(2016,2017,2019)$ have explained through research that it is more common for words to contain more within language competitors and that greater experience of inhibition in early bilinguals can be a contributing factor to the less taxing task of selecting competition from within language compared to between languages.

\section{CONCLUSION}

In conclusion, the results of this study have illustrated through the presence of cross-linguistic influence in bilinguals that the two languages in the bilinguals mind exist in a state of coactivation regardless of their age of acquisition, consistent with previous studies conducted. However, the age of acquisition of a bilingual's second language differentiates the type of cross-linguistic influence that a bilingual is likely to face when processing their second language. During second language processing, late bilinguals are more likely to face within competition of their second language as compared to early bilinguals. However in a condition where both within and between language competition is present when processing a second language, early bilinguals who would often face competition from within the language in contrast with late bilinguals would face competition from between their languages. Additionally, it is interesting to note that both early and late bilinguals are similar to some extend as demonstrated by the results in which both groups of bilinguals face equal amount of competition from a between language competitor when only that competitor is present during second language processing. Although the age of acquisition can be attributed as a factor for such differences, further studies need to examine how proficiency affects the cross-linguistic influences face by bilinguals as both the age of acquisition is closely linked to the level of proficiency of a bilingual. Additionally, the current study is only limited to a small sample 
size of four participants. Hence, future research should aim to examine a larger sample size in order to further increase the validity of this study.

\section{ACKNOWLEDGEMENT}

\section{This research was supported by the research grant FRGS/1/2017/SSIO1/UKM/01/}

\section{REFERENCES}

Abutalebi, J. (2008). Neural processing of second language representation and control. Acta Psychologica, 128(3), 466-478. doi: 10.1016/j.actpsy.2008.03.014

Antoniou, M. (2019). The advantages of bilingualism debate. Annual Review of Linguistics, 5, 1-21. https://doi.org/10.1146/annurev-linguistics-011718-011820

Aryadoust, V., \& Ang, B. H. (2019). Exploring the frontiers of eye tracking research in language studies: a novel co-citation scientometric review. Computer Assisted Language Learning, 1-36.

Beardsmore, H. B. (1986). Bilingualism: Basic Principles ( $2^{\text {nd }}$ Ed). United Kingdom: Multilingual Matters.

Berken, J. A., Chai, X., Chen, J. K., Gracco, V. L., \& Klein, D. (2016). Effects of Early and Late Bilingualism on Resting-State Functional Connectivity. The Journal of Neuroscience, 36(4), 1165-1172. doi: 10.1523/JNEUROSCI.1960-15.2016

Bialystok, E. (2017). The bilingual adaptation: How minds accommodate experience. Psychological Bulletin, 143(3), 233-262. doi:10.1037/bul0000099

Bialystok, E., \& Martin, M. M. (2004). Attention and inhibition in bilingual children: evidence from the dimensional change card sort task. Developmental Science, 7, 325-339. https://doi.org/10.1111/j.14677687.2004.00351.X

Blumenfeld, H. K., \& Marian, V. (2005). Covert bilingual language activation through cognate word processing: An eye-tracking study. In Proceedings of the Annual Meeting of the Cognitive Science Society. Vol. 27, (27).

Blumenfeld, H. K., \& Marian, V. (2007). Constraints on parallel activation in bilingual spoken language processing: Examining proficiency and lexical status using eye-tracking. Language and cognitive processes, 22(5), 633-660.

Blumenfeld, H. K., \& Marian, V. (2013). Parallel language activation and cognitive control during spoken word recognition in bilinguals. Journal of Cognitive Psychology, 25(5), 547-567.

Conklin, K., \& Pellicer-Sánchez, A. (2016). Using eye-tracking in applied linguistics and second language research. Second Language Research, 32(3), 453-467.

Fricke, M., Zirnstein, M., Navarro-Torres, C., \& Kroll, J. (2018). Bilingualism reveals fundamental variation in language processing. Bilingualism: Language and Cognition, 22(1), 1-8. doi: $10.1017 / \mathrm{S} 1366728918000482$.

Fromkin, V., Rodman, R., \& Hyams, N. (2007). An introduction to language (10th ed.). Boston, MA: Cengage Learning.

Gerard, L. D. \& Scarborough, D. L. (1989). Language-specific lexical access of homographs by bilinguals. Journal of Experimental Psychology: Learning, Memory, and Cognition, $\quad$ 15, 305-313. https://doi.org/10.1037/0278-7393.15.2.305

Green, D. W. (1998). Mental control of the bilingual lexico-semantic system. Bilingualism: Language and Cognition, 1, 67-81. https://doi.org/10.1017/S1366728998000133

Grosjean, F. (2001). The bilingual's language modes. In J.Nicol (Eds.), One mind, two languages: Bilingual language processing (pp. 1-22). Oxford: Blackwell.

Grosjean, F. (2018). The Listening Bilingual: Speech Perception, Comprehension, and Bilingualism. New Jersey: HOB: John Wiley \& Sons Inc.

Hajar Abdul Halam. (2020). Covid-19 as It Happens: Insights from language Corpora. 3L: The Southeast Asian Journal of English Language Studies, 26(2), 1 - 23. http://doi.org/10.17576/3L-2020-2602-01

Hamers, J. F., \& Blanc, M. H. A. (1983). Bilinguality \& bilingualism. New York, NY: Cambridge University Press 1989.

Kidd, E., Chan, A. \& Chiu. J. (2015). Cross-linguistic influence in simultaneous Cantonese-English bilingual children's comprehension of relative clauses. Bilingualism: Language and Cognition, 18(3), 438452. doi:https://doi.org/10.1017/S1366728914000649

Kovelman, I., Baker, S. A., \& Petitto, L. A. (2008). Age of first bilingual language exposure as a new window into bilingual reading development. Bilingualism (Cambridge, England), $\quad$ 11(2), $\quad 203-223$. doi: $10.1017 / \mathrm{S} 1366728908003386$ 
Leikin, M. (2012). The effect of bilingualism on creativity: Developmental and educational perspectives. International Journal of Bilingualism, 17, 431-447. https://doi.org/10.1177/1367006912438300

Macizo. P. (2016) Phonological coactivation in the bilinguals' two languages: Evidence from the color naming task. Bilingualism: Language and Cognition, 19(2), 361-375. https://doi.org/10.1017/S136672891500005X

Marian, V., Bartolotti, J., Rochanavibhata, K. B., \& Hernandez, A. E. (2017). Bilingual Cortical Control of Between- and Within-Language Competition. Scientific Reports, 7,11763. https://doi.org/10.1038/s41598-017-12116-w

Mishina-Mori, S. (2019). Cross-linguistic influence in the use of objects in Japanese/English simultaneous bilingual acquisition. International Journal of Bilingualism. doi: 10.1177/1367006919826864

Moradi, H. (2014). An Investigation through different types of bilinguals and bilingualism. International Journal of Humanities \& Social Science Studies (IJHSSS), 1(2), 107-112.

Or-Kan, Soh. (2016). Examining the reading behaviours and performances of sixth-graders for reading instruction: evidence from eye movements. Journal of e-Learning and Knowledge Society, 12(4), 63-79.

Sarah Yusri, Or-Kan, Soh. (2019). Examining University Students' Reading Performances and Behaviors with the Use of Eye-Trackers. International Journal of Academic Research in Business and Social Sciences, 9(8), 114-123. DOI: 10.6007/IJARBSS/v9-i8/6221

Supakorn, P. (2020). A Genre and Collocational Analysis of Consequences, Results and Outcomes. 3L: The Southeast Asian Journal of English Language Studies, 26(3), 1 - 16. http://doi.org/10.17576/3L-20202603-01

Or-Kan, Soh. (2017). Processing academic science reading texts through context effects: Evidence from eye movements. EURASIA Journal of Mathematics, Science and Technology Education, 13(3), 771-790.

Peristeri, E., Tsimpli, I. M., Sorace, A., \& Tsapkini, K. (2017). Language interference and inhibition in early and late successive bilingualism. Bilingualism: Language and Cognition, 21(5), 1009-1034. https://doi.org/10.1017/S1366728917000372

Rabia, S. (2019). The effect of degrees of bilingualism on metacognitive linguistic skills. International Journal of Bilingualism, 23(5), 1064-1086. https://doi.org/10.1177/1367006918781060

Ransdell, S. E. \& Fischler, I. (1987). Memory in a monolingual mode: When are bilinguals at a disadvantage? Journal of Memory and Language, 26, 392-405. https://doi.org/10.1016/0749-596X(87)90098-2

Ratiu, I., Hout, M. C., Walenchok, S. C., Azuma, T., \& Goldinger, S. C. (2017). Comparing Visual search and eye movements in bilinguals and monolinguals. Attention, Perception, \& Psychophysics, 79(6), 1695-1725. doi: 10.3758/s13414-017-1328-3

Rossi, E., Diaz, M., Kroll, J. F. \& Dussias, P. E. (2017). Late Bilinguals Are Sensitive to Unique Aspects of Second

Language Processing: Evidence from Clitic Pronouns Word-Order. Frontiers in Psychology, 8(342), 1-13. doi: 10.3389/fpsyg.2017.00342

Salleh, R., Kawaguchi, S., Jones, C. \& Biase, B.D. (2016). The development of plural expressions in a MalayEnglish bilingual Child. Asiatic: IIUM Journal of English Language and Literature, 10(2), 60-81.

Soh, Or-Kan., Hazita, A., \& Ho, S. M. (2020). A Systematic Review on Bilingualism and Language Processing from 2015-2019. 3L: The Southeast Asian Journal of English Language Studies, 26(1), 1 - 14. http://doi.org/10.17576/3L-2020-2601

Strik, N. (2016). Wh-questions in child bilingual acquisition of French: Derivational complexity and crosslinguistic influence. Canadian Journal of Linguistics, 57 (1), 133-151 doi: https://doi.org/10.1017/S000841310000223

Tanenhaus, M., Magnuson, J., Dahan, D. \& Chambers, C. (2000). Eye movements and lexical access in spoken language comprehension: Evaluating a linking hypothesis between fixations and linguistic processing. Journal of Psycholinguistic Research, 29, 557-580. doi: 10.1023/A:1026464108329

Valian, V. 2015. Bilingualism and cognition. Bilingualism: Language and Cognition, 18(1), 3-24. doi:10.1017/S1366728914000522

Watkins, M. J. \& Peynircioglu, Z. F. (1983). On the nature of word recall: Evidence for linguistic specificity. Journal of Verbal Learning and Verbal Behavior, 22, 336- 394. https://doi.org/10.1016/S00225371(83)90246-3

Whitford V., Pivneva I., Titone D. (2016). Eye Movement Methods to Investigate Bilingual Reading. In Heredia R., Altarriba J., Cieślicka A. (Eds.), The Bilingual Mind and Brain Book Series. Methods in Bilingual Reading Comprehension Research (Vol 1). New York, NY: Springer.

Zirnstein, M., van Hell, J. G., \& Kroll, J. F. (2019). Cognitive control and language ability contribute to online reading comprehension: Implications for older adult bilinguals. International Journal of Bilingualism, 23(5), 971-985. https://doi.org/10.1177/1367006918763143 


\section{APPENDIX A}

1. Name:

2. Age (years; months):

3. Gender:

4. Have you ever studied or learned a second language in terms of listening, speaking, reading, or writing? (Circle one): Yes / No

5. Indicate the age at which you started using each of the languages you have studied or learned in the following environments.

\begin{tabular}{|c|c|c|c|c|c|}
\hline Language & At Home & With Friends & At School & At Work & Online Games \\
\hline & & & & & \\
\hline & & & & & \\
\hline & & & & & \\
\hline & & & & & \\
\hline
\end{tabular}

6. Estimate how many hours per day you spend engaged in the following activities in each of the languages you have studied or learned.

Language: $\quad$ Language:

Watching television:

(hrs)

(hrs)

Listening to radio:

(hrs)

(hrs)

Reading for fun:

(hrs)

(hrs)

Reading for school/work:

(hrs)

(hrs)

Writing emails to friends:

(hrs)

(hrs)

Writing for school/work:

(hrs)

(hrs)

7. In which language do you communicate best or feel most comfortable in terms of listening, speaking, reading, and writing in each of the following environments?

\begin{tabular}{|l|l|l|l|l|}
\hline & Listening & Speaking & Reading & Writing \\
\hline At Home & & & & \\
\hline With Friends & & & & \\
\hline At School & & & & \\
\hline At Work & & & & \\
\hline
\end{tabular}

8. Please comment below to provide any other information about your language background or usage. 


\section{APPENDIX B}

Participant 1 (late bilingual)

\begin{tabular}{lcccccccccc}
\hline Condition & Screen & Screen & Screen & Screen & Screen & Screen & Screen & Screen & Screen & Screen \\
& $\mathbf{1}$ & $\mathbf{2}$ & $\mathbf{3}$ & $\mathbf{4}$ & $\mathbf{5}$ & $\mathbf{6}$ & $\mathbf{7}$ & $\mathbf{8}$ & $\mathbf{9}$ & $\mathbf{1 0}$ \\
\hline Between Competition & 0 & 0 & 0 & 1 & 0 & 0 & 0 & 0 & 0 & 0 \\
Within Competition & 0 & 0 & 0 & 0 & 0 & 0 & 0 & 0.5 & 0 & 0 \\
Simultaneous Competition & & & & & & & & & & \\
$\quad$ Between & 0 & 0 & 1 & 0 & 0 & 0 & 0 & 0 & 0 & 0 \\
$\quad$ Within & 0 & 0 & 0 & 0 & 0 & 0.5 & 0 & 0 & 0 & 0 \\
\hline
\end{tabular}

Participant 2 (late bilingual)

\begin{tabular}{lcccccccccc}
\hline Condition & Screen & Screen & Screen & Screen & Screen & Screen & Screen & Screen & Screen & Screen \\
& $\mathbf{1}$ & $\mathbf{2}$ & $\mathbf{3}$ & $\mathbf{4}$ & $\mathbf{5}$ & $\mathbf{6}$ & $\mathbf{7}$ & $\mathbf{8}$ & $\mathbf{9}$ & $\mathbf{1 0}$ \\
\hline Between Competition & 0 & 0 & 0 & 0 & 0 & 0 & 1 & 0 & 0 & 0 \\
Within Competition & 0 & 0 & 1 & 0 & 0 & 0 & 0 & 0 & 0 & 0 \\
Simultaneous Competition & & & & & & & & & & \\
$\quad$ Between & 0 & 1 & 0 & 0 & 0.5 & 0 & 0 & 0 & 0 & 0 \\
$\quad$ Within & 0 & 0 & 0 & 0 & 0 & 0 & 1 & 0 & 0 & 0 \\
\hline
\end{tabular}

Participant 3 (early bilingual)

\begin{tabular}{lcccccccccc}
\hline Condition & Screen & Screen & Screen & Screen & Screen & Screen & Screen & Screen & Screen & Screen \\
& $\mathbf{1}$ & $\mathbf{2}$ & $\mathbf{3}$ & $\mathbf{4}$ & $\mathbf{5}$ & $\mathbf{6}$ & $\mathbf{7}$ & $\mathbf{8}$ & $\mathbf{9}$ & $\mathbf{1 0}$ \\
\hline Between Competition & 0 & 0 & 0 & 0 & 0 & 0 & 1 & 0 & 0 & 0 \\
Within Competition & 0 & 1 & 0 & 0 & 1 & 0 & 0 & 0 & 0 & 0 \\
Simultaneous Competition & & & & & & & & & & \\
$\quad$ Between & 0 & 0 & 1 & 0 & 0 & 0 & 0 & 0 & 0 & 0 \\
$\quad$ Within & 0 & 0 & 0 & 1 & 0 & 0 & 1 & 0 & 1 & 0 \\
\hline
\end{tabular}

Participant 4 (early bilingual)

\begin{tabular}{lcccccccccc}
\hline Condition & Screen & Screen & Screen & Screen & Screen & Screen & Screen & Screen & Screen & Screen \\
& $\mathbf{1}$ & $\mathbf{2}$ & $\mathbf{3}$ & $\mathbf{4}$ & $\mathbf{5}$ & $\mathbf{6}$ & $\mathbf{7}$ & $\mathbf{8}$ & $\mathbf{9}$ & $\mathbf{1 0}$ \\
\hline Between Competition & 0 & 0 & 0 & 0 & 0 & 0 & 0 & 1 & 0 & 0 \\
Within Competition & 0 & 0 & 0 & 0 & 0 & 0 & 0 & 0 & 0 & 0 \\
Simultaneous Competition & & & & & & & & & & \\
$\quad$ Between & 0 & 0 & 0 & 0 & 0 & 0.5 & 0 & 0 & 0 & 0 \\
$\quad$ Within & 0 & 1 & 0 & 1 & 0 & 0 & 0 & 0 & 0 & 0 \\
\hline
\end{tabular}

